\title{
Effects of Tongluotangtai recipe on serum pain substances 5-HT, B-EP, histamine and bradykinin in rats with painful diabetic peripheral neuropathy model of streptozotocin (STZ).
}

\author{
Li Haizhen ${ }^{1,2}$, Zheng Guanlin ${ }^{3}$, Zhuang Xianghua ${ }^{4}$, Wang Cailing ${ }^{4}$, Chen Shihong ${ }^{*}$ \\ ${ }^{1}$ Department of Endocrinology, the Second Hospital of Shandong University, PR China \\ ${ }^{2}$ Department of Endocrinology, People's Hospital of Dongying District, Shandong, PR China \\ ${ }^{3}$ Department of Endocrinology, Taishan Shandong Vocational Nursing College, the Second Hospital of Shandong \\ University, PR China
}

\begin{abstract}
Objective: To investigate the effect of Tongluotangtai decoction on 5-HT, $\beta$-EP, histamine and bradykinin in serum of STZ rats with pain-related diabetic neuropathy.

Methods: The rat model of diabetic peripheral neuropathy was made by intraperitoneal injection of STZ. The rats were divided into control group, model group, Tongluo sugar group and phenytoin. The rats were administrated with saline, Tongluo sugar Thai or phenytoin sodium daily, and the levels of 5HT, $\beta$-EP, histamine and bradykinin in the serum of each group were measured after $3 \mathrm{w}, 5 \mathrm{w}$ and $9 \mathrm{w}$.

Results: After $3 \mathrm{w}, 5 \mathrm{w}$ and $9 \mathrm{w}$ of drug intervention, the levels of 5-HT, histamine and bradykinin in the model group were significantly higher than those in the control group $(P<0.05)$ and the level of $\beta$-EP was significantly reduced. Compared with the model group, the contents of histamine and bradykinin in Tongtao Tangtai group and phenytoin group were significantly decreased and the level of $\beta$-EP was significantly reduced. Compared with the rats in the phenytoin group, the contents of histamine and bradykinin in Tongtao Suantai group and phenytoin group were significantly decreased and the level of $\beta$-EP was significantly reduced.

Conclusion: Tongtao Tangtai decoction can significantly reduce the level of 5-HT, histamine and bradykinin in STZ-induced diabetic neuropathy model rats, increase the content of $\beta$-EP and exert a significant anti-pain effect.
\end{abstract}

Keywords: Diabetic peripheral neuropathy model, Tongluo sugar Thai side, 5-HT, $\beta$-EP, Histamine, Bradykinin.

Accepted on November 29, 2017

\section{Introduction}

Diabetes Mellitus (MD) is an important disease influencing people's health. With the improvement of people's diet, its incidence rate and mortality rate increase. It is predicted incidence rate over the world in 2013 will excess 333 million, only secondary to cardiovascular diseases and tumor, the third non-infectious diseases [1,2]. The complications of diabetes are multiple, of which, Diabetic Peripheral Neuropathy (DPN) is one of the most common complications, the main factor causing disability and death of diabetes patients. According to the clinical studies, the symptom manifestation of DPN is pain. The clinical manifestations are spontaneous burning or lightning -like pain in lower abdomen, end of lower limbs, and lateral part of thigh. During onset, it will cause great pain, it is difficult to tolerate $[3,4]$. Therefore, finding DNP effective method can not only relieve pain of patients, also has an important significance in reducing disability and death rate induced by diabetes. Chinese herbs are the unique treasure in
China. There are many reports show that Tongluotangtai Polypharmaceutical formula can relieve secretion of DNP rat inflammatory cellular factors, promote recovery of nerve function and play the prevention and treatment of DNP [5]. 5HT, $\beta$-EP, histamine and bradykinin are the important pain indexes. Study on level changes of substances above has significance on DNP pain relieving and degree. Therefore, this study select STZ to produce peripheral neurological lesion model of rats pain diabetes and explore the influences of Tongluotangtai poly-pharmaceutical formula on Tongluotangtai poly-pharmaceutical formula of rats serum pain substance model, which provide experience for clinical study. Now results reported as followed. 


\section{Materials and Methods}

\section{Experimental animals}

Ethical approval was given by the medical ethics committee of the second hospital of Shandong University with the following reference number: 2016008 , Healthy adult SD 180 rats with the weight of 180 to $220 \mathrm{~g}$ for 2 to 4 months bought from Beijing vital river experimental animals technology Co., Ltd. Qualified number: scxk (jing) 2016-0001. All animals fed in the criteria condition. The specific conditions include $12 \mathrm{~h}$ light or dark circulation under 20 to $23^{\circ} \mathrm{C}$. The relative humidity is $50 \%$. All procedures followed "Experimental nursing and use guidance" of NIH.

\section{Reagent and instruments}

Tongluotangtai poly-pharmaceutical formula was made by preparation room of affiliated hospital in Chengdu university of Chinese medicine. The production batch number was 20071027. The main ingredients included berberine, Rhizoma Corydalpis, Scrophularia ningpoensis, Cortex Lycii, Silkworm excrement, leech, White mustard seed, borneol and so on. This drug was made by concentration and extraction of herbs above. When we used it, adding normal saline to the needed concentration. The effects of $1 \mathrm{ml}$ extract were equal to $10 \mathrm{~g}$ crude herbs.

STZ bought from America Sigma Company; phenyton sodium bought from Shanxi Yunpeng pharmaceutical Co., Ltd. SFDA approval number was H14020776. ELISA bought from Shenzhen Dakewe Biotech Co., Ltd.

Instrument: ELISA bought from ThermoFisher Scientific (China) Co., Ltd. Type number was NanoDrop1000; lowtemperature high-speed centrifugal machine bought from ThermoFisher Scientific (China) Co., Ltd. Micropipettor bought from Eppendorf Co., Ltd (China); glucose meter bought from America Johnson company.

\section{Experimental methods and grouping}

180 rats were selected 30 cases according to weight differences after one-week normal feeding. These 30 rats were divided into three groups, each 10, they were three-week group, five-week group and nine-week group. 30 rats above were not given diabetes modeling. Other 150 rats were given diabetes modeling. The modeling method reported as the following. There were positive 90 rats with pain sensitivity of diabetes by computer random selection, they were divided into model three-week group, five-week group, nine-week group, Tongluotangtai three-week group, five-week group, nine-week group, phenytoin sodium three-week group, five-week group, nine-week group, each 10 rats.

\section{Modeling method}

Giving fating and water deprivation before modeling. Then we injected 2\% STZ solution by abdominal cavity (using $0.1 \mathrm{~mol} / 1$ citric acid buffer to place, $\mathrm{PH} 4.2$ ). Injection dosage was set as
$53 \mathrm{mg} / \mathrm{kg}$. After $72 \mathrm{~h}$, we measured blood glucose of tail in rats. Rats with blood glucose of $16.7 \mathrm{mmol} / \mathrm{l}$ were the successful modeling rats. The control group was given 0.1 $\mathrm{mol} / \mathrm{l}$ citric acid buffer of the same volume.

The measurement methods of diabetes pain sensitivity: after 21 $\mathrm{d}$ of diabetes modeling, the rats were given mechanical withdrawal reflection test. The specific test included placing metal mesh on a plexiglass case $(22 \times 12 \times 22 \mathrm{~cm})$. The modeling rats were placed in case for $15 \mathrm{~min}$. Then we used 10 $\mathrm{g}$ nylon wire to mechanically stimulate middle part of feet in hind leg of rats for $4 \mathrm{~s}$ continuously. Positive reaction was the feet lift or licking feet, no reaction meant negative. The stimulation of rats was from weak to strong, each intensity for 10 times. The median interval was about $3 \mathrm{~s}$. The intensity of five foot withdrawal was PWMT. Rats who not reached to pain sensitivity threshold value had been excluded.

\section{Administration methods}

After $21 \mathrm{~d}$ of STZ modeling, rats in this study were given intragastric administration. Concentration and collocation method: Tongluotangtai formula was $10 \mathrm{mg} / \mathrm{kg} / \mathrm{d}$ (normal saline collocation); phyenytoin sodium was $10 \mathrm{mg} / \mathrm{kg} / \mathrm{d}$ (phyenytoin sodium was crushed with warm water into suspension); the blank control group and model group were given normal saline with the same volume. They were given once administration to three-week, five-week and nine-week.

\section{Observation indexes}

First, blood glucose of tails in rats were measured before modeling, $3 \mathrm{w}, 5 \mathrm{w}$ and $9 \mathrm{w}$ after modeling; second, after $3 \mathrm{w}$, $5 \mathrm{w}$ and $9 \mathrm{w}$ after administration intervention, rats were given anesthesia, then we collected blood in aorta abdominalis, centrifugation serum. Using ELISA to measure the level of pain-relief substances such as 5-HT, $\beta$-EP, histamine and bradykinin in serum.

\section{Data management}

We used SPSS 17.0 software to study and deal with all data in this study. Measurement data used $(\overline{\mathrm{x}} \pm \mathrm{s})$ and t-test. Enumeration data used $\mathrm{n} \%$ and $\chi^{2}$ test. $\mathrm{P}<0.05$, there were statistical differences.

\section{Results}

\section{Blood glucose conditions of tails in rats after $72 \mathrm{~h}$ of modeling in various groups}

After giving STZ modeling of rats in various groups, blood glucose concentration of rats in model group, Tongluotangtai formula group and phenytoin sodium group higher than the control group obviously $(\mathrm{P}<0.05)$, there were no obvious differences in blood glucose of rats between model group, 
Effects of Tongluotangtai recipe on serum pain substances 5-HT, ?-EP, histamine and bradykinin in rats with painful diabetic peripheral neuropathy model of streptozotocin (STZ)

Tongluotangtai formula group and phenytoin sodium group $(\mathrm{P}>0.05)$, it can applied to the following test (Table $1, \overline{\mathrm{x}} \pm \mathrm{s}$ ).

Table 1. Blood glucose conditions of tails in rats after $72 \mathrm{~h}$ of modeling in various group $(\bar{x} \pm s)$.

\begin{tabular}{lll}
\hline Group & Number $(\mathbf{n})$ & Blood glucose $(\mathrm{mmol} / \mathbf{l})$ \\
\hline The control group & 10 & $7.15 \pm 1.45$ \\
\hline The model group & 10 & $21.67 \pm 3.27^{\mathrm{a}}$ \\
\hline Tongluotangtai formula group & 10 & $22.04 \pm 4.02^{\mathrm{a}}$ \\
\hline phenytoin sodium group & 10 & $21.94 \pm 3.27^{\mathrm{a}}$ \\
\hline
\end{tabular}

Note: compared with the control group, ${ }^{\mathrm{a}} \mathrm{P}<0.05$

\section{Comparison in serum pain substances level of rats in various groups after $3 w$ of drug intervention}

Compared with the control group, 5-HT, histamine and bradykinin of rats in the model group increased obviously after $3 \mathrm{w}$ of drug intervention $(\mathrm{P}<0.05), \beta$-EP decreased obviously $(\mathrm{P}<0.05)$; compared with rats in the model group, 5-HT, histamine and bradykinin of rats in Tongluotangtai formula group and phenytoin sodium group decreased obviously $(\mathrm{P}<0.05), \beta$-EP increased obviously $(\mathrm{P}<0.05)$; and compared with rats in phenytoin sodium group, 5-HT, histamine and bradykinin of rats in Tongluotangtai formula group and phenytoin sodium group decreased obviously $(\mathrm{P}<0.05), \beta$-EP increased obviously $(\mathrm{P}<0.05$, Table 2$)$.

Table 2. Comparison in serum pain substances level of rats in various groups after $3 w$ of drug intervention ( $n g / l, \bar{x} \pm s$ ).

\begin{tabular}{|c|c|c|c|c|c|c|c|c|}
\hline Group & Number (n) & 5-HT & & $\beta$-EP & & Histamin & & $\begin{array}{l}\text { Bradykini } \\
\text { n }\end{array}$ \\
\hline $\begin{array}{l}\text { The control } \\
\text { group }\end{array}$ & 10 & $\begin{array}{l}21.84 \\
5.01\end{array}$ & \pm & $\begin{array}{l}51.35 \\
10.64\end{array}$ & \pm & $\begin{array}{l}23.57 \\
5.94\end{array}$ & \pm & $\begin{array}{l}5.87 \\
1.04\end{array}$ \\
\hline $\begin{array}{l}\text { The } \\
\text { group }\end{array}$ & 10 & $\begin{array}{l}59.46 \\
10.27^{a}\end{array}$ & \pm & $\begin{array}{l}15.07 \\
3.40^{\mathrm{a}}\end{array}$ & \pm & $\begin{array}{l}82.04 \\
18.43^{a}\end{array}$ & \pm & $\begin{array}{l}18.24 \\
3.26^{a}\end{array}$ \\
\hline $\begin{array}{l}\text { Tongluotangtai } \\
\text { formula group }\end{array}$ & 10 & $\begin{array}{l}46.57 \\
8.21^{\mathrm{abc}}\end{array}$ & \pm & $\begin{array}{l}23.46 \\
6.17^{\mathrm{abc}}\end{array}$ & \pm & $\begin{array}{l}57.46 \\
8.26^{\mathrm{abc}}\end{array}$ & \pm & $\begin{array}{l}11.55 \\
2.71^{\mathrm{abc}}\end{array}$ \\
\hline $\begin{array}{l}\text { phenytoin } \\
\text { sodium group }\end{array}$ & 10 & $\begin{array}{l}49.43 \\
9.07^{a b}\end{array}$ & \pm & $\begin{array}{l}19.04 \\
5.37^{\mathrm{ab}}\end{array}$ & \pm & $\begin{array}{l}64.18 \\
11.74^{\text {ab }}\end{array}$ & \pm & $\begin{array}{l}14.25 \\
3.14^{\mathrm{ab}}\end{array}$ \\
\hline
\end{tabular}

Note: compared with the control group, ap $<0.05$; compared with the model group, ${ }^{\mathrm{b}} \mathrm{P}<0.05$; compared with phenytoin sodium group, ${ }^{\mathrm{C}}<0.05$

\section{Comparison in serum pain substances level of rats in various groups after 5 w of drug intervention}

Compared with the control group, 5-HT, histamine and bradykinin of rats in the model group increased obviously after $5 \mathrm{w}$ of drug intervention $(\mathrm{P}<0.05), \beta$-EP decreased obviously $(\mathrm{P}<0.05)$; compared with rats in the model group, 5-HT, histamine and bradykinin of rats in Tongluotangtai formula group and phenytoin sodium group decreased obviously $(\mathrm{P}<0.05), \beta$-EP increased obviously $(\mathrm{P}<0.05)$; and compared with rats in phenytoin sodium group, 5-HT, histamine and bradykinin of rats in Tongluotangtai formula group and phenytoin sodium group decreased obviously $(\mathrm{P}<0.05), \beta$-EP increased obviously $(\mathrm{P}<0.05$, Table 3$)$.

Table 3. Comparison in serum pain substances level of rats in various groups after $5 \mathrm{w}$ of drug intervention ( $\mathrm{ng} / \mathrm{l}, \bar{x} \pm s$ ).

\begin{tabular}{|c|c|c|c|c|c|c|c|c|}
\hline Group & $\begin{array}{l}\text { Number } \\
\text { (n) }\end{array}$ & 5-HT & & $\beta$-EP & & Histamine & & $\begin{array}{l}\text { Bradykini } \\
\text { n }\end{array}$ \\
\hline $\begin{array}{l}\text { The } \\
\text { group }\end{array}$ & 10 & $\begin{array}{l}22.65 \\
7.13\end{array}$ & \pm & $\begin{array}{l}49.55 \\
13.57\end{array}$ & \pm & $\begin{array}{l}20.74 \\
5.71\end{array}$ & \pm & $6.84 \pm 1.67$ \\
\hline $\begin{array}{l}\text { The } \\
\text { group }\end{array}$ & 10 & $\begin{array}{l}93.46 \\
18.46^{a}\end{array}$ & \pm & $\begin{array}{l}15.34 \\
3.46^{a}\end{array}$ & \pm & $\begin{array}{l}127.59 \\
25.47^{a}\end{array}$ & \pm & $\begin{array}{l}27.42 \\
5.74^{\mathrm{a}}\end{array}$ \\
\hline $\begin{array}{l}\text { Tongluotangtai } \\
\text { formula group }\end{array}$ & 10 & $\begin{array}{l}45.18 \\
7.98^{\mathrm{abc}}\end{array}$ & \pm & $\begin{array}{l}26.97 \\
5.74^{\mathrm{abc}}\end{array}$ & \pm & $\begin{array}{l}56.44 \\
6.72^{\text {abc }}\end{array}$ & \pm & $\begin{array}{l}11.55 \\
2.71^{\mathrm{abc}}\end{array}$ \\
\hline $\begin{array}{l}\text { Phenytoin } \\
\text { sodium group }\end{array}$ & 10 & $\begin{array}{l}52.76 \\
9.47^{\mathrm{ab}}\end{array}$ & \pm & $\begin{array}{l}21.42 \\
4.47^{a b}\end{array}$ & \pm & $\begin{array}{l}62.58 \\
8.29^{a b}\end{array}$ & \pm & $\begin{array}{l}14.25 \\
3.14^{\mathrm{ab}}\end{array}$ \\
\hline
\end{tabular}

Note: compared with the control group, ap $<0.05$; compared with the model group, ${ }^{\mathrm{b}} \mathrm{P}<0.05$; compared with phenytoin sodium group, ${ }^{\mathrm{C}} \mathrm{P}<0.05$.

\section{Comparison in serum pain substances level of rats in various groups after $9 w$ of drug intervention}

The results of nine-week intervention were similar to the fiveweek intervention. Compared with the control group, 5-HT, histamine and bradykinin of rats in the model group increased obviously $(\mathrm{P}<0.05), \quad \beta$-EP decreased obviously $(\mathrm{P}<0.05)$; compared with rats in the model group, 5-HT, histamine and bradykinin of rats in Tongluotangtai formula group and phenytoin sodium group decreased obviously $(\mathrm{P}<0.05), \beta-\mathrm{EP}$ increased obviously $(\mathrm{P}<0.05)$; and compared with rats in phenytoin sodium group, 5-HT, histamine and bradykinin of rats in Tongluotangtai formula group and phenytoin sodium group decreased obviously ( $\mathrm{P}<0.05), \beta$-EP increased obviously $(\mathrm{P}<0.05$, Table 4$)$.

Table 4. Comparison in serum pain substances level of rats in various groups after $9 w$ of drug intervention ( $n g / l, \bar{x} \pm s$ ).

\begin{tabular}{|c|c|c|c|c|c|c|c|c|}
\hline Group & $\begin{array}{l}\text { Number } \\
\text { (n) }\end{array}$ & 5-HT & & $\beta$-EP & & Histamine & & $\begin{array}{l}\text { Bradykini } \\
\mathrm{n}\end{array}$ \\
\hline $\begin{array}{l}\text { The } \\
\text { group }\end{array}$ & 10 & $\begin{array}{l}25.94 \\
5.13\end{array}$ & \pm & $\begin{array}{l}52.87 \\
15.74\end{array}$ & \pm & $\begin{array}{l}21.05 \\
3.88\end{array}$ & \pm & $6.21 \pm 0.79$ \\
\hline $\begin{array}{l}\text { The } \\
\text { group }\end{array}$ & 10 & $\begin{array}{l}115.74 \\
20.46^{a}\end{array}$ & \pm & $\begin{array}{l}12.95 \\
2.55^{a}\end{array}$ & \pm & $\begin{array}{l}138.46 \\
26.74^{\mathrm{a}}\end{array}$ & \pm & $\begin{array}{l}27.49 \\
4.19^{a}\end{array}$ \\
\hline $\begin{array}{l}\text { Tongluotangtai } \\
\text { formula group }\end{array}$ & 10 & $\begin{array}{l}32.97 \\
5.71^{\mathrm{abc}}\end{array}$ & \pm & $\begin{array}{l}27.21 \\
3.84^{\mathrm{abc}}\end{array}$ & \pm & $\begin{array}{l}43.89 \\
5.74^{\mathrm{abc}}\end{array}$ & \pm & $\begin{array}{l}12.55 \\
2.71^{\mathrm{abc}}\end{array} \quad \pm$ \\
\hline $\begin{array}{l}\text { Phenytoin } \\
\text { sodium group }\end{array}$ & 10 & $\begin{array}{l}41.08 \\
6.89^{a b}\end{array}$ & \pm & $\begin{array}{l}21.77 \\
2.13^{a b}\end{array}$ & \pm & $\begin{array}{l}54.94 \\
6.49^{a b}\end{array}$ & \pm & $\begin{array}{l}15.84 \\
3.74^{\mathrm{ab}}\end{array}$ \\
\hline
\end{tabular}

Note: compared with the control group, aP $<0.05$; compared with the model group, ${ }^{\mathrm{b}} \mathrm{P}<0.05$; compared with phenytoin sodium group, ${ }^{\mathrm{C}} \mathrm{P}<0.05$.

\section{Discussion}

At present, treatment for DNP in clinic only can be relieved not be treated completely. The sharp pain caused by DNP recurrence onset will bring great pain to patients. Pain caused by DNP have characteristics of limb onset, symmetrical onset, more severe at night and so on, it accompanies with feeling 
loss $[6,7]$. Therefore, prompt DNP pain relief has an important significance in treatment of diabetes patients. In TCM theory, the main reasons of pain is Qi and blood stasis, thus causing qi stagnation and pain; chronic pain will cause qi and blood consumption, internal injury in liver, liver qi stagnation, thus leading to qi stagnation and pain $[8,9]$.

Jing-yue complete work pain in the chest and abdomen has recorded that pain can be caused by deficiency or excess. Patients with long-time pain most belong to deficiency, patients with acute pain most belong to excess. The main ingredients of tongluotangtai extract include berberine, Rhizoma Corydalpis, Scrophularia ningpoensis, Cortex Lycii, Silkworm excrement, leech, White mustard seed, borneol and so on, of which, berberine has significant effects of antiinflammation, resolving heatness, lowering blood lipid and anti-oxidant, can inhibit inflammation accumulation of diabetes patients in vivo. Rhizoma Corydalpis has good effects of easing pain and local anesthesia. Herbal truth-seeking has recorded that whatever qi and blood, patients who have stagnation, taking Rhizoma Corydalpis will be benefit for smoothing qi because of its warm nature, so the qi and blood can circulate smoothly; Scrophularia ningpoensis can clear away heatness, cool blood, nourish yin, reduce fire, relieve toxin and remove stagnation; Cortex Lycii has effects of cooling blood, removing steam-heat, clearing away lung and reducing fire; silkworm excrement and leech can resolve stasis to prevent and treat cardiovascular diseases; White mustard seed can warm lung, remove phlegm and regulate qi. Bingpian can remove stagnation, smooth meridian and stop pain. Combination of these herbs can significantly relieve pain cause y qi and blood stasis of DPN patients [10,11]. Clinical studies show that Tongluotangtai formula can effectively relieve clinical symptoms of DNP and improve conduction of nerve through regulation of whole body, it has good effects on the prevention and treatment of DNP [10]. Reports of Zhang also show that Tongluotangtai formula can significantly inhibit JNK signal pathway of rats with peripheral neural lesions of diabetes, has anti-inflammation effect, thus protecting nerve obviously $[12,13]$. The reports about the pain relief of Tongluotangtai formula on DNP are rare. Therefore, this study explores the influences of Tongluotangtai formula on 5-HT, $\beta$ $\mathrm{EP}$, histamine and bradykinin in serum of rats in DPN model caused by STZ.

$\beta$-EP is a kind of important endogenous opioid peptide, can play the sedation and analgesia function combined with opioid receptor, especially in inflammation control [14,15]. 5-HT as a kind of monoamine neurotransmitter, can regulate and control horizontal downward damaging stimulation of spinal cord, play the function of lowering the pain sensitivity of body $[16,17]$. Bradykinin can produce the function similar to morphine combined with morphine receptor in brain, it has been verified in many reports that have significant inflammation pain promoting function, but its effects and mechanism are still unclear [15]. Histamine mainly exists in neuron and mastocyte of brain, is aminergic neurotransmitter, it participates in multiple physiological function of central pivot and peripheral part $[18,19]$. There are reports showing that histamine level can significantly promote pain threshold of body. The recent studies has found that phenytoin sodium has significant analgesia effect, can regulate release of multiple neurotransmitter of brain to avoid over excitation of neuron and inhibit abnormal discharge of feeling neuron through multiple pathways to relieve pain, as well as promote the tolerance of volume on pain through anti-anxiety and sedation. It has been used as positive drug to inhibit pain in many studies [20]. Results of this study show that we measure 5-HT, $\beta$-EP, histamine and bradykinin in serum of rats in the third, fifth and ninth week after administration of Tongluotnagtai formula and phenytoin sodium for DNP rats. The results show that 5-HT, histamine and bradykinin in the model group increased obviously, while $\beta$-EP level decreased obviously; histamine and bradykinin in serum of rats in Tongluotnagtai formula group and phenytoin sodium group decreased obviously, while $\beta$-EP level increased obviously; furthermore, Tongluotnagtai formula has more significant effects.

In conclusion, Tongluotnagtai formula can significantly lower 5-HT, $\beta$-EP, histamine and bradykinin in serum of rats in painful DPN model caused by STZ, increase $\beta$-EP level, thus play significant anti-pain function.

\section{References}

1. Chen YL, Qiao YC, Xu Y. Serum TNF- $\alpha$ concentrations in type 2 diabetes mellitus patients and diabetic nephropathy patients: a systematic review and meta-analysis. Immunol Lett 2017; 186: 52-58.

2. Farabi SS, Carley DW, Quinn L. Glucose variations and activity are strongly coupled in sleep and wake in young adults with type 1 diabetes. Biol Res Nurs 2017; 19: 249-257.

3. Trippe BS, Barrentine LW, Curole MV. Nutritional management of patients with diabetic peripheral neuropathy with L-methylfolate-methylcobalaminpyridoxal-5-phosphate: results of a real-world patient experience trial. Curr Med Res Opin 2016; 32: 219-227.

4. Negi G, Nakkina V, Kamble P. Heme oxygenase-1, a novel target for the treatment of diabetic complications: focus on diabetic peripheral neuropathy. Pharmacol Res 2015; 102: 158-167.

5. Zhang WY, Xie CG, Du L. Influence of Tongluo Tangtai recipe on inflammatory cytokines in rats with diabetic peripheral neuropathy. J Guangzhou Univ Trad Chinese Med 2016; 33: 55-59.

6. Covert BP, Nobles RH. Successful spinal cord stimulator trial and permanent implant in patient with diabetic peripheral neuropathy on chronic dual antiplatelet therapy. Pain Phys 2015; 18: 905-909.

7. DSouza M, Kulkarni V, Bhaskaran U. Diabetic peripheral neuropathy and its determinants among patients attending a tertiary health care centre in Mangalore, India. J Public Health Res 2015; 4: 450.

8. Luo C. TCM understanding on the pain. Clin J Chinese Med 2015; 7: 86-87. 
9. Zhao H, Zhao H. Study process of Chinese herbs in treating DPN. Med Health 2016; 103.

10. Zhou XH, Xie CG. The clinical study of tongluotangtai formula on DPN patients SNCV. Liaoning Univ Chinese Med J 2012; 14: 62-64.

11. Song CY, Wang H, Du L. The influences of tongluotangtai formula on spontaneous type-2 DP N Caspase-3 kinase protein expression. Lishizhen Med Mater Medica Res 2016; 27: 16-18.

12.Zhang W, Xie CG, Du L. The influences of Tongluotangtaion DPN rate JNK signal reduction pathway and inflammatory factors. Guid J Trad Chinese Med Pharmacol 2016; 22: 13-16.

13. Jiang AJ, Shen GM, Wang H. Effects of Yiqihuoxuetongluo recipe on the expression of p75NTR and TrkA in dorsal root ganglion of diabetic peripheral neuropathy rats. Chinese J Clin Pharmacol Ther 2016.

14. Yue HY, Han LC, Zheng QQ. Effects of dezocine combined with sufentanil self-controlled analgesia on serum betaendorphin content, inflammation and oxidative stress reaction after Iobectomy. J Hainan Med Univ 2015; 21: 227-230.

15. Ping S, Fei W. Effect of dezocine combined with sufentanil patient-controlled intravenous analgesia on general pain and inflammatory mediators after laparoscopic hepatectomy. J Hainan Med Univ 2017; 23.

16. Liu DD, Guo JS, Guo QY. Study on xiongma decoction in intervening behaviors symptoms, peripheral blood and5-HT in cerebral tissue with nitroglycerin migraine. China J Trad Chinese Med Pharm 2015; 5:1708-1711.

17. Zhang X, Chen M, Xie R. Comparison analysis of the clinical effects of sufentanil and dezocine on obese puerpera-controlled intravenous analgesia after cesarean section. Chinese J Obes Metabol Dis 2017.

18. Chen P, Hu P, Gao J. Study on the effect of pamidronate disodium on the pain stress and bone metabolic status of patients with metastatic tumor in bones. J Clin Exp Med 2016; 15: 2129-2132.

19. Yin Y, Feng L, Zhou L. Effects of Yishengukang decoction on expression of bone specific alkaline phosphatase, carboxyterminal propeptide of type I procollagen, and carboxyterminal cross linked telepeptide of type I collagen in malignant tumor patients with bone metastasis. J Trad Chinese Med 2017; 37: 30-34.

20. Li JJ, Sui MH, Lin SY. Evaluation of the effects of fireneedle on the levels of 5-HT, HA and PGE2 in rheumatoid arthritis rats by microdialysis. J Jinan Univ 2017; 38: 314-321.

\section{*Correspondence to}

Chen Shihong

Department of Endocrinology

The second hospital of Shandong University

PR China 